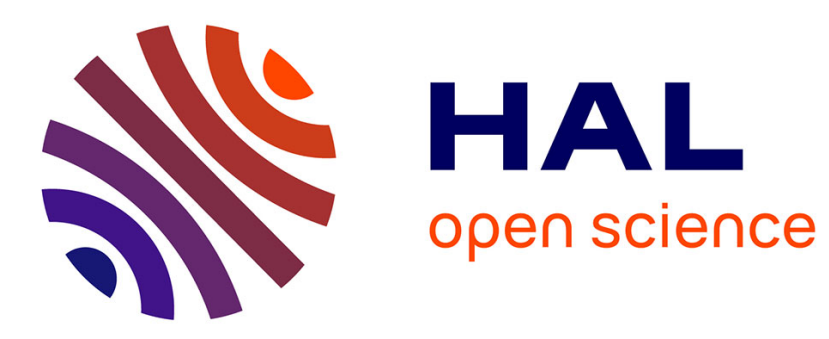

\title{
Physical modeling of three-dimensional intermediate beach morphodynamics
}

Hervé Michallet, Bruno Castelle, Eric Barthélemy, Céline Berni, Philippe Bonneton

\section{- To cite this version:}

Hervé Michallet, Bruno Castelle, Eric Barthélemy, Céline Berni, Philippe Bonneton. Physical modeling of three-dimensional intermediate beach morphodynamics. Journal of Geophysical Research: Earth Surface, 2013, 118 (2), pp.1045-1059. 10.1002/jgrf.20078 . hal-00909153

\section{HAL Id: hal-00909153 https://hal.science/hal-00909153}

Submitted on 16 Aug 2021

HAL is a multi-disciplinary open access archive for the deposit and dissemination of scientific research documents, whether they are published or not. The documents may come from teaching and research institutions in France or abroad, or from public or private research centers.
L'archive ouverte pluridisciplinaire HAL, est destinée au dépôt et à la diffusion de documents scientifiques de niveau recherche, publiés ou non, émanant des établissements d'enseignement et de recherche français ou étrangers, des laboratoires publics ou privés.

$$
\text { Copyright }
$$




\title{
Physical modeling of three-dimensional intermediate beach morphodynamics
}

\author{
H. Michallet, ${ }^{1}$ B. Castelle, ${ }^{2}$ E. Barthélemy, ${ }^{1}$ C. Berni, ${ }^{1}$ and P. Bonneton ${ }^{2}$ \\ Received 5 October 2012; revised 27 April 2013; accepted 30 April 2013; published 10 June 2013.
}

[1] Experiments have been performed in a large wave tank in order to study the morphodynamics of rip current systems. Both accretive and erosive shore-normal wave conditions were applied, the beach evolving through all the states within the intermediate beach classification, under the so-called down-state (accretive) and up-state (erosive) morphological transitions. Results show that any prescribed change in the wave conditions drastically increases the rate at which the morphology changes. The surf zone morphology tends toward a steady state when running a given wave climate for a long duration. We quantitatively describe a full down-state sequence characterized by the progressive evolution of an alongshore-uniform bar successively into a crescentic plan shape, a bar and rip channel morphology, and a terrace. From the analysis of a large data set of dense Eulerian measurements and bathymetric surveys, we depict several feedback mechanisms associated with wave-driven rip current circulation, wave nonlinearities and the seabed evolution. At first, a positive feedback mechanism drives a rapid increase in the rate of morphological change, beach three-dimensionality, and rip intensity. By the time the sandbar evolves into a bar and rip morphology, a negative feedback mechanism, characterized by a decaying beach change rate and an increasing beach alongshore uniformity, overwhelms the former mechanism. An erosive sequence characterized by both an overall offshore bar migration and an increase in beach three-dimensionality is also described.

Citation: Michallet, H., B. Castelle, E. Barthélemy, C. Berni, and P. Bonneton (2013), Physical modeling of three-dimensional intermediate beach morphodynamics, J. Geophys. Res. Earth Surf., 118, 1045-1059, doi:10.1002/jgrf.20078.

\section{Introduction}

[2] Rip currents are powerful, channeled seaward flowing currents of water that are ubiquitous along wave-dominated sandy beaches. They typically extend from the shoreline to the surf zone and, sometimes, past the breakers [Reniers et al., 2009]. Topographically controlled rip currents are induced by breaking waves over three-dimensional (3-D) surf zone sandbars. They are one of the most deadly coastal hazards [e.g., MacMahan et al., 2006; Scott et al., 2007] and a key element of mixing in the nearshore [Dalrymple et al., 2011]. Rip currents also play a role in coastal erosion because they create rip embayments, i.e., megacusps, that expose the beach and the nearby dune to higher rates of erosion during severe storms (i.e., hot-spots, Thornton et al. [2007]). Over the last decades, our understanding

\footnotetext{
${ }^{1} \mathrm{CNRS} /$ Grenoble-INP/UJF-Grenoble 1, Grenoble, France.

${ }^{2}$ CNRS, UMR 5805 EPOC, Université de Bordeaux, Talence CEDEX, France.

Corresponding author: H. Michallet, CNRS/Grenoble-INP/UJFGrenoble 1, LEGI UMR 5519, Grenoble, F-38041, France. (herve.michallet@legi.grenoble-inp.fr)

(C)2013. American Geophysical Union. All Rights Reserved. 2169-9003/13/10.1002/jgrf.20078
}

of rip currents and concurrent surf zone sandbar evolution has increased through a variety of techniques including field and laboratory experiments, nearshore video imaging systems, and mathematical and computer modeling. In the field, acquiring long-term Eulerian and/or Lagrangian measurements of rip current circulations is a challenging task due to energetic conditions. In addition, both rip current circulations and surf zone sandbar morphology permanently evolve as a result of both strong feedbacks between flow, sediment transport and the seabed evolution, and the persistent changes in natural wave conditions and tidal elevation [e.g., Brander, 1999; Bruneau et al., 2009; Austin et al., 2010; MacMahan et al., 2005]. Overall, and despite recent video-based studies addressing the morphodynamic evolution of rip currents with a geometric approach (ignoring depth, e.g., Holman et al. [2006]), studies quantitatively addressing sequence of 3-D sandbar evolution are nonexistent, which is both a major shortcoming for the validation of morphodynamic models and a limitation to our understanding of the morphodynamics of rip current systems.

[3] Wright and Short [1984] used hundreds of visual field observation of waves, nearshore currents, and sandbar morphology of a number of beaches to develop the most widely accepted sequential beach state classification scheme. The 
two end states, the dissipative (D) and the reflective (R), were related to storm waves and prolonged periods of low-energy wave conditions, respectively, with the notable absence of bars and rip currents. In between, within the intermediate states, bars and rip currents are observed. Intermediate beaches were further divided into four substates as, from the more reflective to the more dissipative, low tide terrace (LTT), transverse bar and rip (TBR), rhythmic bar and beach (RBB), and longshore bar trough (LBT). Rip current intensity was found to increase for the (down-state) sequence from LBT to TBR and then to further decrease towards the LTT state. This classification scheme was subsequently corroborated by high-frequency video observations [e.g., Ranasinghe et al., 2004]. It was also extended to include the influence of tides on beaches and surf zones [Masselink and Short, 1993] and to multi-barred beaches [e.g., Lippmann and Holman, 1990; Price and Ruessink, 2011].

[4] Since the pioneering work of Wright and Short [1984], there have been a number of field studies addressing rip current circulations on intermediate beaches [e.g., Brander, 1999; Brander and Short, 2000, 2001; MacMahan et al., 2004a, 2004b, 2005; Bruneau et al., 2009; Austin et al., 2010]. Most of these studies were performed on a weakly evolving intermediate beach bathymetry. The only rip experiment during intermediate beach state transitions is reported in Brander [1999]. A single rip cell circulation was surveyed daily for a full LBT-RBB-TBR-LTT down-state sequence that lasted 12 days. Despite a number of limitations pointed out in Ranasinghe et al. [2004], Brander [1999] found that down-state, accretionary, beach state evolution on intermediate beaches is characterized by an increase in rip current velocity. These results are in line with Wright and Short [1984], except that Brander [1999] found that rip current intensity also increases during the TBR-LTT part of the sequence.

[5] There is a large number of numerical studies addressing topographically controlled rip current circulations with successful comparison with field or laboratory data [e.g., Haas et al., 2003; Haas and Warner, 2009; Reniers et al., 2009; Bruneau et al., 2011]. The mechanism for topographically controlled rip current circulation generation is nearshore wave height variations that are induced by longshore varying bottom bathymetry [e.g., Dalrymple et al., 2011]. In contrast with the fair ability of numerical models to predict mean rip current circulations for a given nearshore bathymetry, nonlinear morphodynamic models still fail to predict the overall evolution of 3-D surf zone sandbars. Numerical models established that, starting from an alongshore-uniform sandbar, 3-D patterns such as rip channels and crescentic bed forms develop through the positive feedback between flow, sediment transport and the evolving bathymetries [e.g., Deigaard et al., 1999; Falqués et al., 2000; Calvete et al., 2005; Smit et al., 2008; Castelle and Ruessink, 2011], and that the presence of standing edge waves is not a necessary requirement [Coco and Murray, 2007]. At best, i.e., when not blowing-up for long-term simulations [e.g., Drønen and Deigaard, 2007; Castelle et al., 2010a], nonlinear morphodynamic models allow the saturation of 3-D patterns [e.g., Garnier et al., 2010; Castelle and Ruessink, 2011; Tiessen et al., 2011], with a typical RBB or TBR state at saturation of the bed form growth. A notable shortcoming is that nonlinear morphodynamic models do not reproduce the up-state sequence during high-energy waves [e.g., Van Enckevort et al., 2004], nor the observed decrease in both rip channel volume and rip current intensity as a result of the down-state TBR-LTT transition [Wright and Short, 1984]. For TBR-LTT transition only did Ranasinghe et al. [2004] claim to simulate this sequence under oblique waves. However, one can argue that the final LTT morphology was more likely an erosive TBR (eTBR) as described by Price and Ruessink [2011]. In addition, TBR-LTT transitions have been widely observed under shore-normal waves [e.g., Wright and Short, 1984; Sénéchal et al., 2009; Price and Ruessink, 2011]. Overall, the negative feedback mechanisms responsible for both up-state and TBR-LTT down-state sequences are not understood. A major reason is the lack of bathymetric and hydrodynamic data during such sequences.

[6] Laboratory experiments have been undertaken in order to study topographically controlled rip current circulation more easily than on natural beaches [Hamm, 1992; Haller and Dalrymple, 2001; Haas and Svendsen, 2002; Kennedy and Thomas, 2004]. These laboratory experiments were all performed with a fixed bed, therefore ignoring the morphodynamics. In contrast, a number of laboratory experiments addressed beach profile evolution. To satisfy the laws of similitude, experiments at scale 1 [e.g., Wang and Kraus, 2005; Guannel et al., 2007] or more recently smallscale experiment with coarse and lightweight sediment [e.g., Grasso et al., 2009] have been performed to address crossshore sandbar behavior. For instance, these experiments allowed investigation of equilibrium beach profiles [e.g., Wang and Kraus, 2005; Grasso et al., 2009] and the impact of beach nourishments [Grasso et al., 2011a]. The respective roles of undertow and wave nonlinearities on sediment transport and resulting cross-shore sandbar migration were also addressed through physical modeling [e.g., Grasso et al., $2011 \mathrm{~b}$ ]. In contrast, despite the obvious success of physical modeling in addressing beach profile evolutions, laboratory experiments on the morphodynamics of 3-D beaches and evolving rip current system are scarce.

[7] In 2008, the first laboratory experiment addressing in detail the morphodynamics of rip current systems was performed in the LHF ("Laboratoire d'Hydraulique de France") multidirectional wave basin. Castelle et al. [2010b] presented some results restricted to drifter measurements on a single incomplete down-state sequence, focusing on the behavior of rip current cells and surf zone retention. In the present contribution, we address the morphological evolutions observed during the complete experiment together with the analysis of a unique data set of dense Eulerian measurements acquired in the rip current systems. For the first time, we provide an extensive quantitative description of the morphodynamics of a rip current system during intermediate beach down-state and up-state transitions. In section 2, we present the experimental setup. The overall morphological evolutions throughout the experiment (section 3) are further detailed in section 4 with discrimination of the downstate and up-state beach state transitions. The detailed spatial and temporal evolution of the hydrodynamics is analyzed in section 5 together with insight into the positive and negative feedback mechanisms. Our findings are further discussed in the framework of intermediate beach schemes in section 6 , and conclusions are stated in section 7 . 


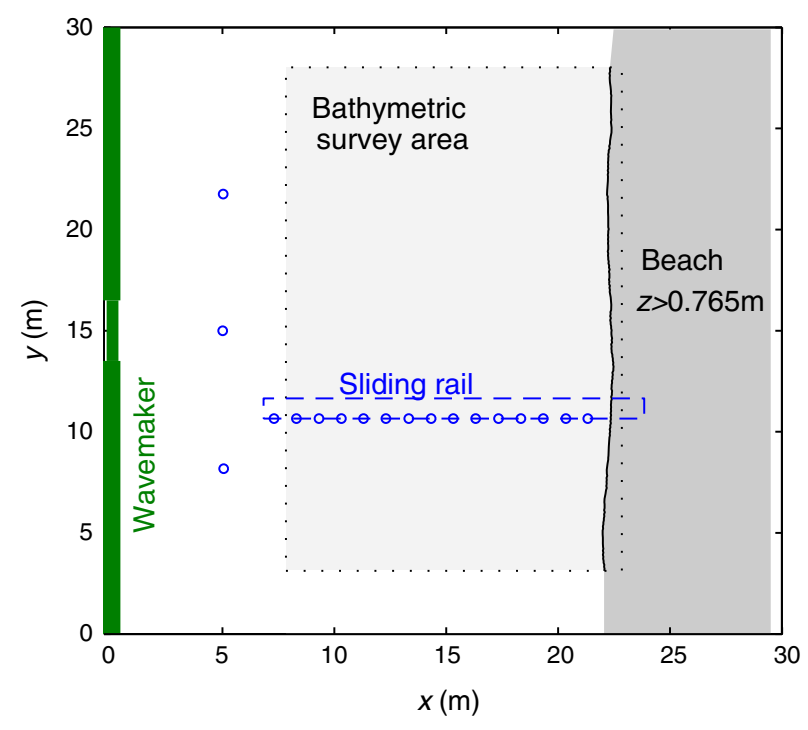

Figure 1. Schematic diagram of the basin with $x$ and $y$, the cross-shore and alongshore coordinates, respectively. The mean water depth is $h_{0}=0.765 \mathrm{~m}$ for $x \leq 6 \mathrm{~m}$. The sandy beach extends from $x \approx 6 \mathrm{~m}$ to $x=26 \mathrm{~m}$. The sliding beam allows for bathymetric survey in the region shaded in grey. Circles indicate positions of the capacitance gauges.

\section{Experimental Set-up}

\subsection{The LHF Wave Tank and Chosen Scaling}

[8] Experiments have been conducted in the LHF $30 \mathrm{~m} \times 30 \mathrm{~m}$ wave basin sketched in Figure 1. The offshore wall is made up of 60 independently controlled pistontype wavemakers. A beam sliding on rails supporting the instruments was designed for measuring the waves along cross-shore transects and the beach topography (Figure 2). The still water level at the wavemaker was $h_{0}=76.5 \mathrm{~cm}$ for all experiments. The chosen length scale of $\approx 1 / 10$ leads to a time scale of $\approx 1 / 3$ to fulfill Froude scaling.

[9] It is difficult to fulfill both Rouse scaling (suspension dynamics) and Shields scaling (threshold for sediment mobility, bed load, ripples, and sheet flow regimes) in small-scale physical models. Grasso et al. [2009] used a light-weight sediment in their experiments in order to correctly reproduce the different sediment transport regimes and consequently the beach morphodynamics. For limiting the costs, natural sediment (fine sand of density 2.65 and median diameter $d_{50}=0.166 \mathrm{~mm}$, corresponding settling velocity $w_{s}=2 \mathrm{~cm} \mathrm{~s}^{-1}$ ) was used in the present experiments. With this choice, Rouse scaling gives a prototype grain size of $d_{50} \approx 0.3 \mathrm{~mm}$. In contrast, the Shields number in the experiments is about half of that of the prototype. Consequently, sand ripples were observed on most of the bed surface (see Figure 2b). The beach was shaped with a basement of gravels covered with a geotextile. The movable bed consisted of a sand layer of at least $10 \mathrm{~cm}$ thick throughout the experiments.

\subsection{Measuring Tools}

[10] The beach morphology was measured by means of a laser profiler mounted on a motorized trolley located on the sliding beam (Figure 2). This measurement technique required emptying the basin before recording the bed elevation. Emptying and subsequent filling of the basin were carried out at a low flow rate in order to prevent impacting on beach morphology. The seabed elevation was recorded with millimeter accuracy every $10 \mathrm{~cm}$ and $1 \mathrm{~cm}$ in the alongshore and cross-shore direction, respectively. As shown in Figure 1, the bathymetric survey zone was restricted by the extension of the sliding beam and covered the area $7.84 \mathrm{~m} \leq$ $x \leq 22.84 \mathrm{~m}$ in the cross-shore direction and $3.12 \mathrm{~m} \leq y \leq$ $28.02 \mathrm{~m}$ alongshore.

[11] The distribution of water surface elevations was measured with 18 high-accuracy capacitive gauges designed by Sogreah Consultants. A conducting wire covered with an isolating coating constitutes the $0.5 \mathrm{~mm}$ diameter sensing element which is firmly maintained across the water surface. The capacitance of this sensor is checked to be linearly dependent on the length of immersed wire and converted into a voltage. All the gauges are carefully cleaned and immersed at least $1 \mathrm{~h}$ before each set of measurements. This procedure avoids any drift with water temperature variations and provides water level measurements with an accuracy of
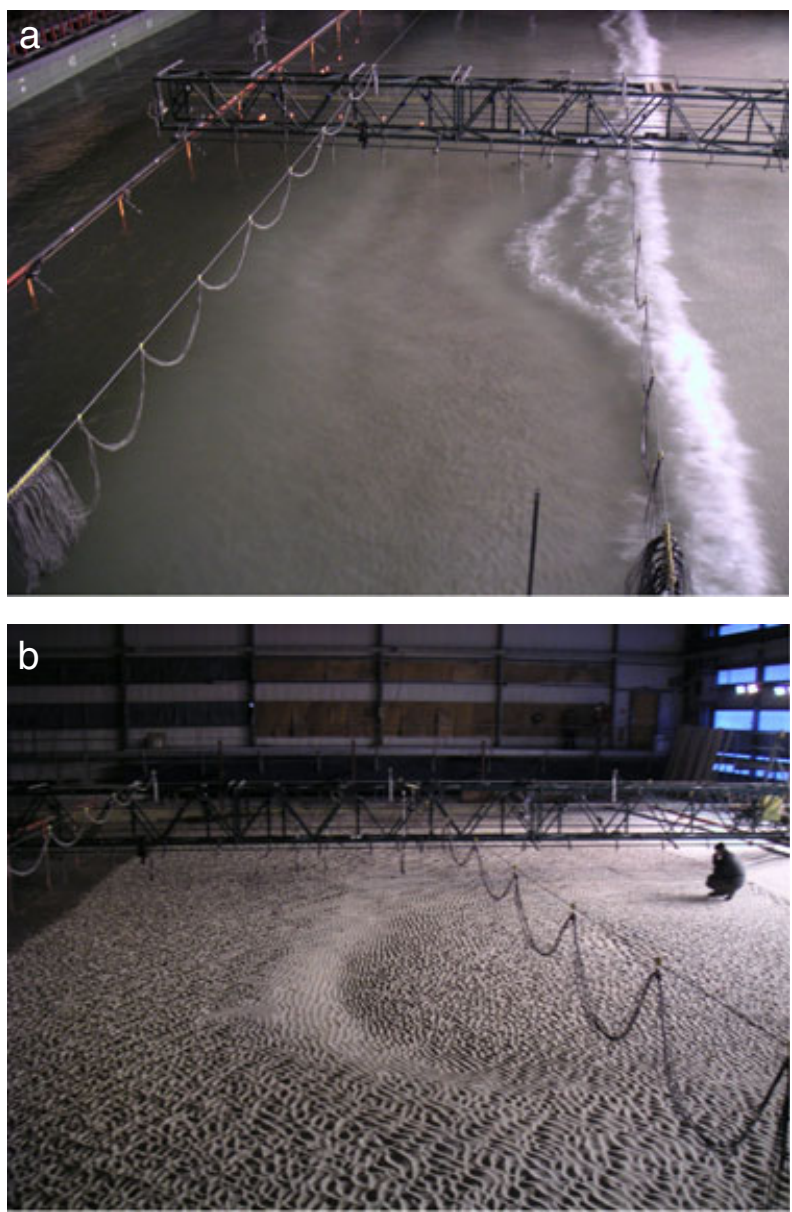

Figure 2. (a) View of a breaking wave front over the threedimensional bathymetry. Wave paddles are seen in the top left corner and the sliding beam supporting the wave gauges ( $1 \mathrm{~m}$ apart) and velocimeters are seen on top of the picture. (b) View of the emptied basin during a bathymetric survey showing the presence of a crescentic sandbar and sand ripples. 
a few tenths of a millimeter. The acquisition frequency was set to $50 \mathrm{~Hz}$.

[12] Velocity measurements were performed with three Acoustic Doppler Velocimeters (ADV Vector from Nortek $\mathrm{AS}$ ) in a side-looking configuration, oriented in the $y$ direction, in order to reduce wake effects in the measurement volume. The three components of the velocity were recorded, but only measurements of the horizontal components are presented here. The measurement volume is estimated to be approximately $1 \mathrm{~cm}^{3}$ and is located between 4 and $8 \mathrm{~cm}$ above the bed according to the various measurement positions. The acquisition frequency was set to $64 \mathrm{~Hz}$.

[13] In addition, the mean wave-driven circulations computed from dense Lagrangian measurements in Castelle et al. [2010b] are further compared to mean Eulerian velocities.

\subsection{Wave Climates}

[14] Shore-normal irregular waves complying to JONSWAP spectra were considered. Three categories of wave conditions were applied, defined by their significant wave height and peak period, namely energetic conditions (A: $\left.H_{m 0}=23 \mathrm{~cm} / T_{p}=2.3 \mathrm{~s}\right)$, moderate conditions with a large period (B: $\left.H_{m 0}=18 \mathrm{~cm} / T_{p}=3.5 \mathrm{~s}\right)$, or a shorter period (C: $\left.H_{m 0}=17 \mathrm{~cm} / T_{p}=2.1 \mathrm{~s}\right)$. These conditions were all chosen so that the dimensionless fall velocity or Dean number $\left(\Omega=H_{m 0} / T_{p} w_{s}\right)$ lies in the intermediate range $(\mathrm{A}: \Omega=5$; $\mathrm{B}$ : $\Omega=2.5$; C: $\Omega=4$ ) as defined by Wright and Short [1984]. A linear combination of 350 random sinusoidal components was used to define each $20 \mathrm{~min}$ wave series. Each wave series was repeated continuously as much as desired during each experiment.

[15] In addition, the generated JONSWAP irregular waves were designed to have less energy at the center of the wave front by imposing a damped motion on chosen wave paddles. This was done in order to create alongshore nonuniformity in the wave breaking for initiating circulations and, as a result, to induce the initial development of the 3$\mathrm{D}$ patterns. The designed wavemaker motions resulted in alongshore variations of $H_{\mathrm{s}}$ as shown in Figure 3 for the seven different wave climates considered. The alongshore nonuniformity of the wave front before the breaking point $(x=7.3 \mathrm{~m}, h \approx 0.6 \mathrm{~m})$ inherits from both the damped motion of some wave paddles and friction along lateral walls. Within a category of $\left(H_{m 0}, T_{p}\right)$ wave conditions, a wave climate is also characterized by the damping at the center of the wave front. The increasing degree in wave paddle damping is numbered from 1 to 3 : for instance, the wave height is smaller at $10 \mathrm{~m} \leq y \leq 20 \mathrm{~m}$ for condition $\mathrm{A} 3$ than for $\mathrm{A} 2$, both conditions nonetheless leading to $H_{\mathrm{s}} \approx 23 \mathrm{~cm}$ at $7 \mathrm{~m} \leq y \leq 10 \mathrm{~m}$.

[16] For a given user-defined wave climate, the morphological evolutions have little influence on the wave front at $x=7.3 \mathrm{~m}$. This can be seen in the weak scattering of the wave height data for a given wave climate in Figure 3. For instance, several black dots at a same alongshore position account for climate A2 at different stages of beach evolution.

\subsection{Procedure}

[17] Each experiment consisted of a series of 7 to 24 twenty minute wave sequences, depending on the amount of morphological changes expected. The bathymetry was surveyed between each experiment. The sliding rail was moved

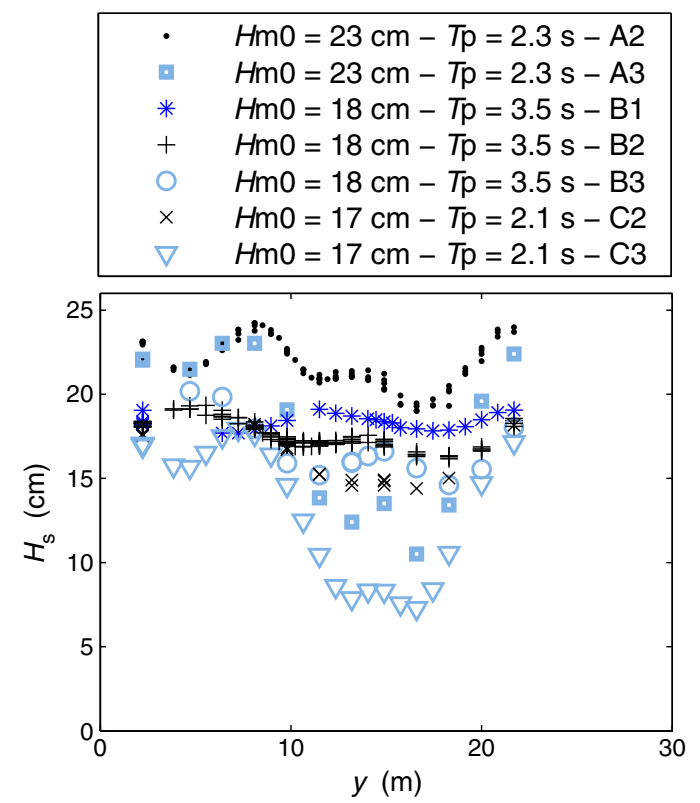

Figure 3. Alongshore distribution of significant wave height measured at $x=7.3 \mathrm{~m}$ (for a mean water depth of about $0.6 \mathrm{~m}$ ) for the different wave climates.

during wave action at the end of each wave sequence in order to inspect different cross-shore transects. Since the time required to move the rail was less than $30 \mathrm{~s}$, the instruments kept on recording, but only the data after moving the rail was analyzed. Relatively small waves $\left(H_{\mathrm{m} 0}<12 \mathrm{~cm}\right)$ were produced during the first $4 \mathrm{~h}$ of the experiments in order to both smooth the bed out and determine the best locations for positioning the measuring instruments.

[18] Velocity measurements in the boundary layer, along with bed erosion processes, have been reported by Berni et al. [2012]. Nonetheless, vertically integrated instantaneous sediment fluxes (including the bed load over the ripples or in the sheet flow layer) that require high-resolution and colocated both velocity and sediment concentration measurements, are not presented here. Nevertheless, the highresolution (in both space and time) bathymetric surveys presented in section 4 produce a valuable picture of the net sediment transport, as will be discussed further in section 5 .

\section{Synthetic View of the Rip Current System Morphological Evolution}

[19] Alongshore-averaged beach profiles (for $3.12 \mathrm{~m} \leq$ $y \leq 18.2 \mathrm{~m})$ are shown in Figure 4. An overall accretion of the beach face was first obtained over a $62 \mathrm{~h}$ duration of mainly B2 wave conditions. For larger and shorter waves (A2 conditions between 66:00 and 100:40), an overall erosion was observed. The accretive and erosive sequences correspond to the so-called down-state and up-state wave transitions (i.e., changes from high to low, and low to high wave energies, respectively).

[20] The detailed description of the morphological evolutions of a rip current system will be presented in detail in section 4. A synthetic view of the time evolution of the morphodynamics and the rip current intensity throughout the experiment is shown in Figure 5 together with the sequence 


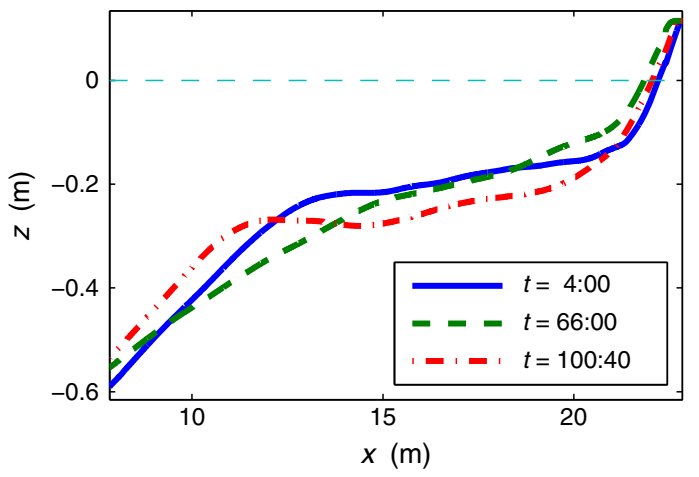

Figure 4. Alongshore-averaged beach profiles at the three main stages of the experiments.

of applied wave climates in Figure 5a. The time evolution of the mean water depth in the surf zone $(x \geq 14 \mathrm{~m})$ at three representative transects (Figure $5 \mathrm{c}$ ) indicates distinct sequences of rip channel formation (until $t \approx 30 \mathrm{~h}$, as shown by the increasing water depth in the rip current axis at $y \sim$ $11 \mathrm{~m}$ ), and subsequent filling (completed at $t \approx 60 \mathrm{~h}$ ). This is followed by the erosive sequence $(66: 00 \leq t \leq 100: 40)$.

[21] The seabed alongshore nonuniformity is quantified as follows:

$$
\sigma_{z}=\left|\left[\frac{1}{y_{2}-y_{1}} \int_{y_{1}}^{y_{2}}(z(x, y)-\overline{z(x)})^{2} \mathrm{~d} y\right]^{1 / 2}\right|
$$

with $y_{1}=3.12 \mathrm{~m}$ and $y_{2}=18.2 \mathrm{~m}$ to cover the main rip current system as will be seen later on, $\overline{z(x)}$ is the alongshore mean cross-shore profile between $y_{1}$ and $y_{2}$ and the notation |. | denotes the spatial averaging over the cross-shore surveyed region $(7.84 \leq x \leq 22.84 \mathrm{~m})$. The time series of $\sigma_{z}$ is shown in Figure $\overline{5} \mathrm{~d}$. It first increases during rip channel formation and further decreases during the channel filling. It subsequently increases again during the erosive phase.

[22] The rate of morphological change is quantified as the ratio of depth variation to time between bathymetric surveys. The absolute value of this velocity is averaged over the domain of interest $\left(7.84 \leq x \leq 22.84 \mathrm{~m}, y_{1} \leq y \leq y_{2}\right)$ and plotted versus time in Figure $5 \mathrm{e}$. Large values are obtained immediately after each change in wave climate, in particular from $\mathrm{C} 2$ to $\mathrm{B} 2$ at $t=9: 40$, from B3 to $\mathrm{A} 2$ at $t=66: 00$, from $\mathrm{A} 2$ to $\mathrm{C} 3$ at $t=100: 40$, and from C3 to A3 at $t=108: 20$. By keeping wave forcing $\left(H_{m 0}, T_{p}\right)$ the same but changing the wave paddle damping (at $t=37: 20, t=40: 00$ and $t=59: 40$ ), the bottom change rate is less affected. Besides, the bottom change rate first increases during the rip channel formation, and then decreases during the rip channel filling.

[23] Mean Eulerian velocities in the rip channel alignment are compared to the Lagrangian measurements described in Castelle et al. [2010a] in Figure 5f. The measurements indicate that the near-bed mean current is approximately twice the surface current transporting the drifters. This will be discussed further in section 5 . Noteworthy, the mean velocity in the rip channel is maximum when the bottom evolution velocity is maximum at $t \approx 20 \mathrm{~h}$. This is the signature of a positive feedback mechanism during the rip channel formation: the 3-D evolution enhances the rip current intensity that in turn enhances the morphological changes rate and the beach three-dimensionality, and so on. This stage is a.

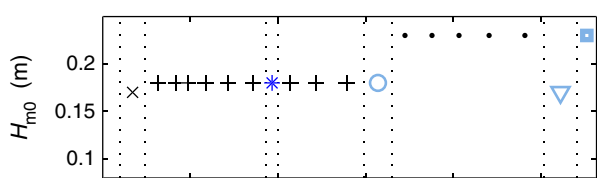

b.

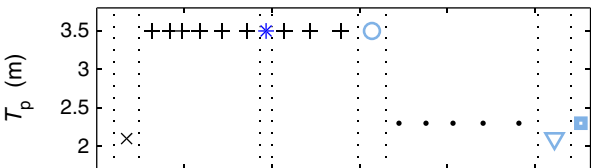

C.

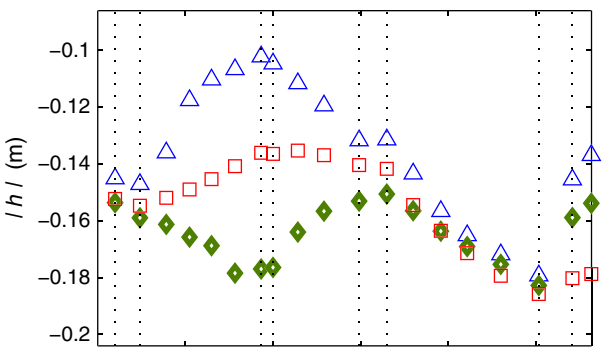

d.

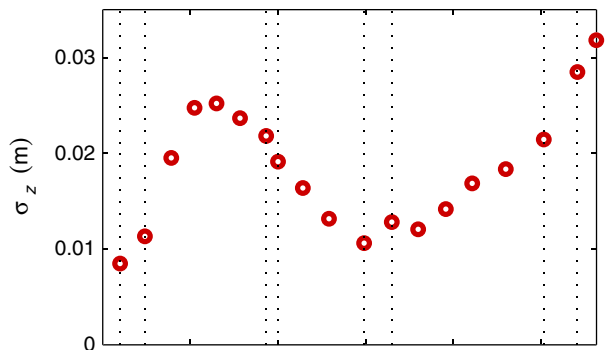

e.

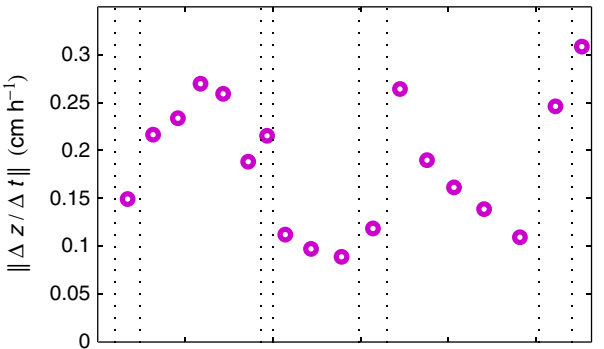

f.

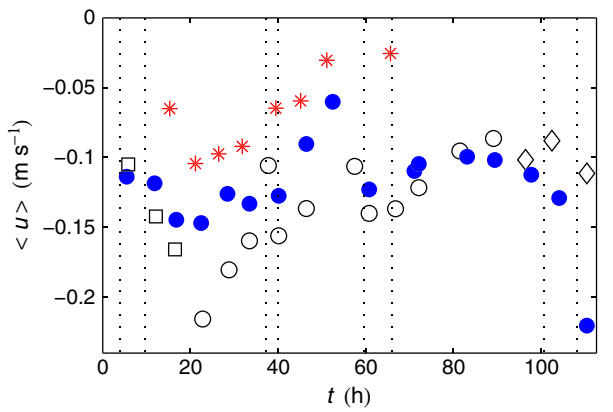

Figure 5. Time series throughout the experiments of the following: (a) significant wave height of the wave front; (b) peak period (the symbols refer to those in Figure 3); (c) mean water depth at the upper beach $(14 \mathrm{~m} \leq x \leq 22.8 \mathrm{~m})$ : at $y=$ $18.3 \mathrm{~m}$ (triangles), at $y=10.7 \mathrm{~m}$ (diamonds) and for $3.1 \mathrm{~m} \leq$ $y \leq 18.3 \mathrm{~m}$ (squares); (d) alongshore seabed nonuniformity $\sigma_{z} ;$ (e) domain-averaged absolute bottom evolution velocity; (f) maximum of the offshore mean velocities at the bar crest (dots: $x=13.1$ ) and at the trough (squares: $x=16.2$, circles: $x=14.7$, diamonds: $x=15.7$ ) and Lagrangian rip current velocity (asterisks). 


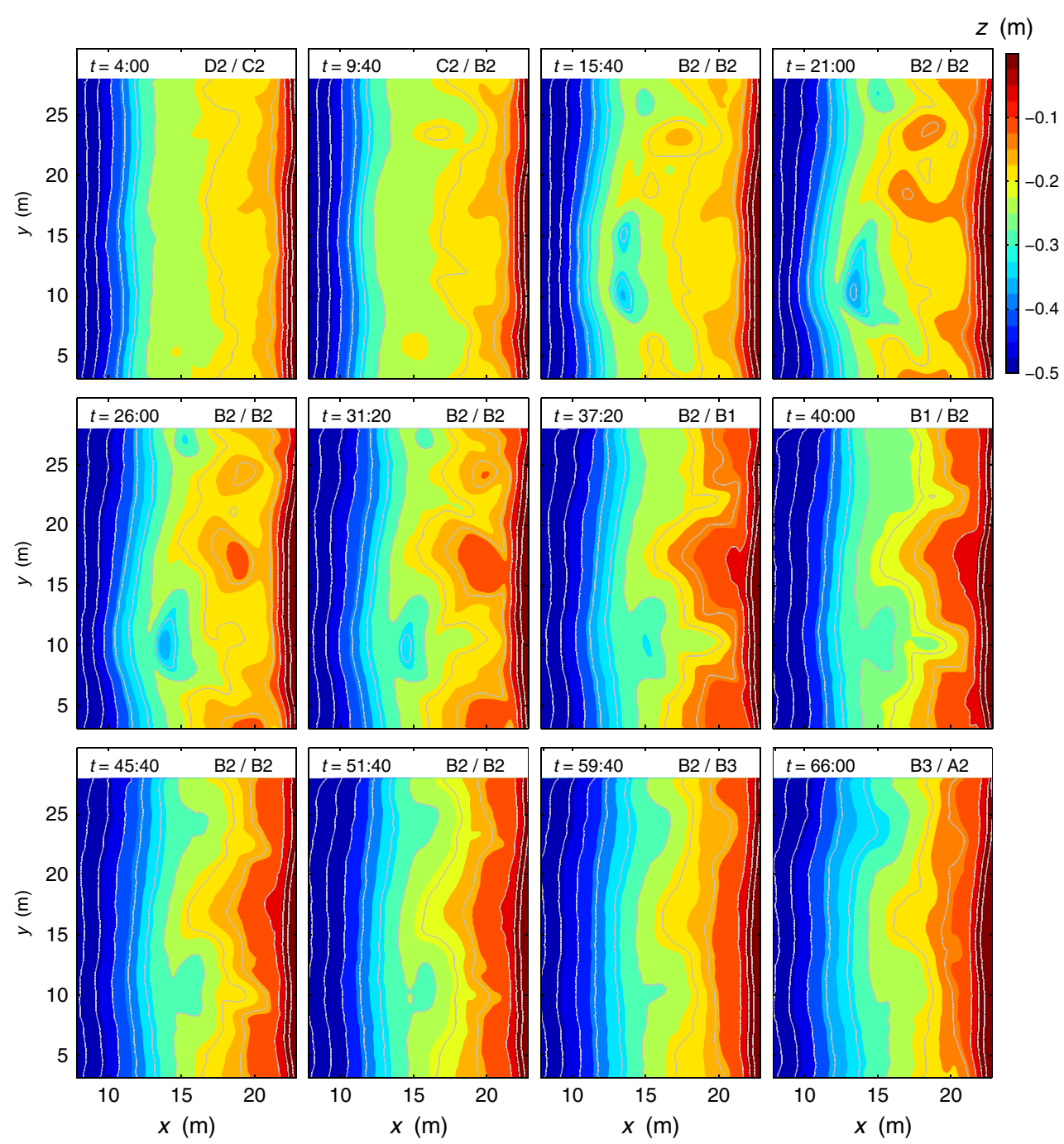

Figure 6. Bathymetries during the accretive sequence, $t$ referring to the time at which the bathymetry was surveyed, with indication of the previous/following wave climate. Isobaths every $4.5 \mathrm{~cm}$ are plotted in grey line.

characterized by an increasing alongshore nonuniformity of the seabed morphology and an overall accretion. Afterwards, a contrasting negative feedback mechanism is observed during the rip decay as the rip current weakens together with a decrease in both beach alongshore nonuniformity and beach change rate. At the transition from positive to negative feedback $(t \approx 30 \mathrm{~h})$, the overall accretion is fairly completed (Figure 5c).

[24] During the erosive sequence (66:00 $\leq t \leq 100: 40$ in Figure 5), the bottom evolution velocity decreases steadily as the rip current intensity stays fairly constant, despite a regular increase in the alongshore variability of the flow patterns. Since the rate of change of the alongshore variability remains significant after more than $34 \mathrm{~h}$ of beach evolution, this sequence is likely incomplete as far as beach equilibrium is considered.

\section{Detailed Morphological Evolutions}

[25] In this section we describe the morphological evolutions observed during the experiments. We first depict the full accretionary down-state sequence from LBT to LTT beach states (Figures 6-8). The erosive sequence is then analyzed (Figure 9).

\subsection{Accretionary Down-State Sequence}

[26] Figure 6 shows the time evolution of the beach morphology. The beach is reasonably uniform alongshore at both the beginning and the end of the accretionary sequence. The transition between these states is characterized by the formation, development, and further decay of three-dimensional patterns. In particular, a rip channel is clearly visible between $t=26: 00$ and 40:00 at $y \simeq 10 \mathrm{~m}$. The state at $t=66: 00$ is chosen as the reference state, as relatively little morphological changes are observed during the preceding wave sequence. A corresponding reference state cross-shore profile $\left(z_{0}(x)\right.$ plotted as a dashed line in Figure 4$)$ is defined as the alongshore-averaged bathymetry in the region (3.12 $\mathrm{m} \leq y \leq 18.2 \mathrm{~m}$, approximately half the basin width) encompassing the main rip current system at $t=66: 00$. In order to emphasize the time evolution of the three-dimensional patterns, the deviation of each 

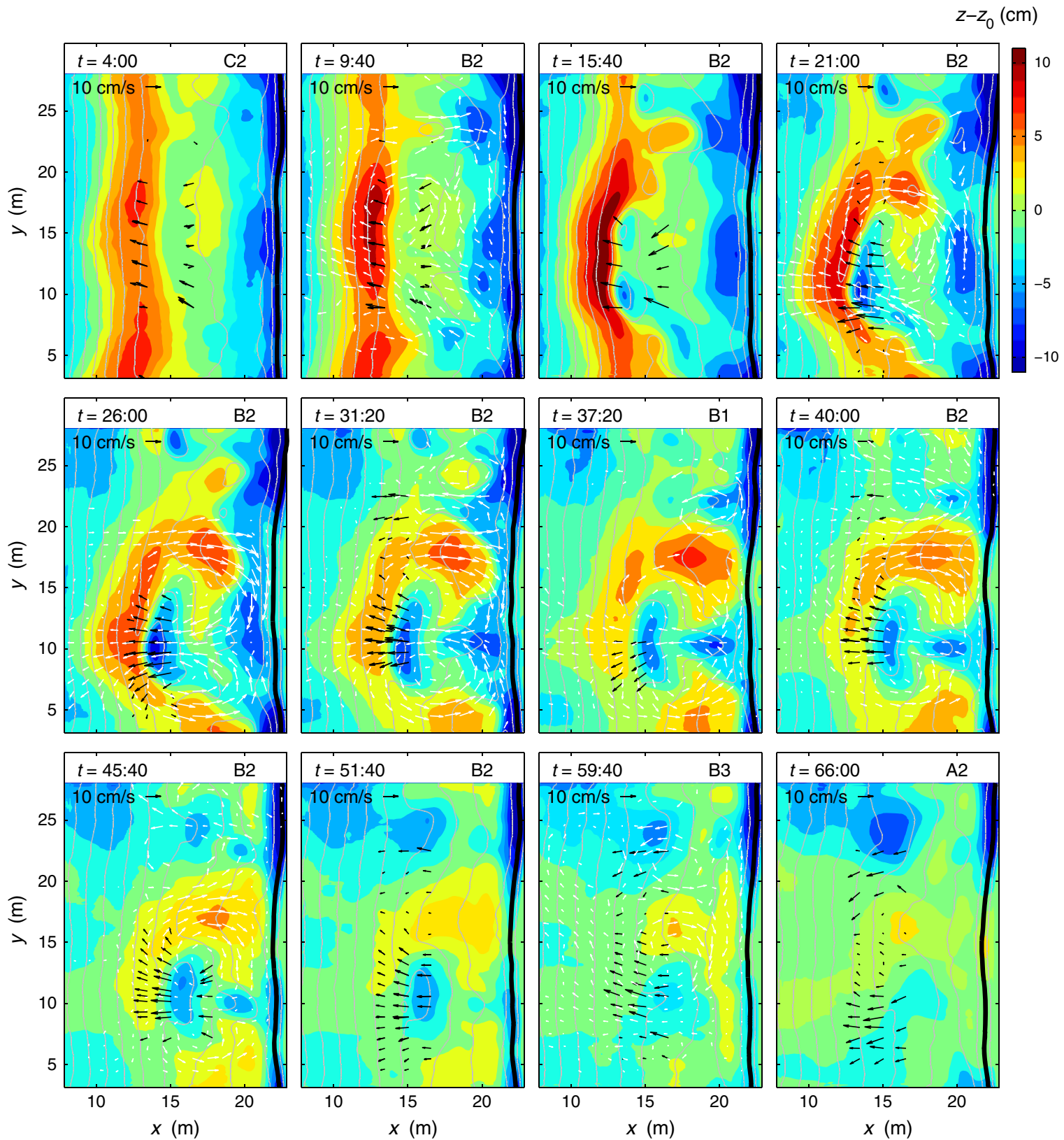

Figure 7. Seabed morphology deviation to the alongshore-averaged beach profile of the quasiequilibrium bathymetry (profile at $t=66: 00$ in Figure 4), with superimposed Eulerian (black arrows) and Lagrangian (white arrows) mean flow velocities of the following wave climate (indicated on top of each panel, $t$ referring to the time at which the bathymetry was surveyed), during the accretive sequence. Isobaths every $4.5 \mathrm{~cm}$ are plotted in grey line, the shoreline is the thick black line.

bathymetry to the reference profile is plotted in Figure 7. A quasi-uniform alongshore bar is present at $t=4: 00$ roughly located at $x \approx 13 \mathrm{~m}$ and the whole bathymetry resembles a LBT state. Between $t=9: 40$ and 15:40, the bar is steepening at $7 \mathrm{~m}<y<17 \mathrm{~m}$. The patterns on the sides at $y \approx 6 \mathrm{~m}$ and $y \approx 23 \mathrm{~m}$ appear as horns $\left(z-z_{0}>0\right)$ and bays $\left(z-z_{0}<0\right)$ alternating shoreward and seaward of the cross-shore position $x \approx 13 \mathrm{~m}$, which corresponds to the position of the initial shore-parallel bar. The LBT morphology evolves into a RBB state with a single crescentic bar at about $8 \mathrm{~m}<y<18 \mathrm{~m}$ that is not connected to the shore. The bar subsequently starts to migrate shoreward at $t=26: 00$ with the formation of shallow shoals alternating with three deeper rip channels at about $y=10 \mathrm{~m}, 21 \mathrm{~m}$, and $26 \mathrm{~m}$. The latter situation is typical of the TBR state. The rip channels are associated with alongshore-oriented feeder channels at $t=26: 00$ and 31:20. At $t=37: 20$ and 40:00, these feeder channels progressively fill up. In the meantime, a decrease in depth of the rip channels is observed, together with the merging of two rip channels (at $y \approx 22 \mathrm{~m}$ and $26 \mathrm{~m}$ at $t=31: 20$ ) into a single rip channel at $y=22 \mathrm{~m}$ at $t=37: 20$. From $t=40: 00$ to $66: 00$, a continuous overall shoreward migration of the bar system is observed together with a decreasing rip channel volume (TBR-LTT transition). At $t=66: 00$, the 

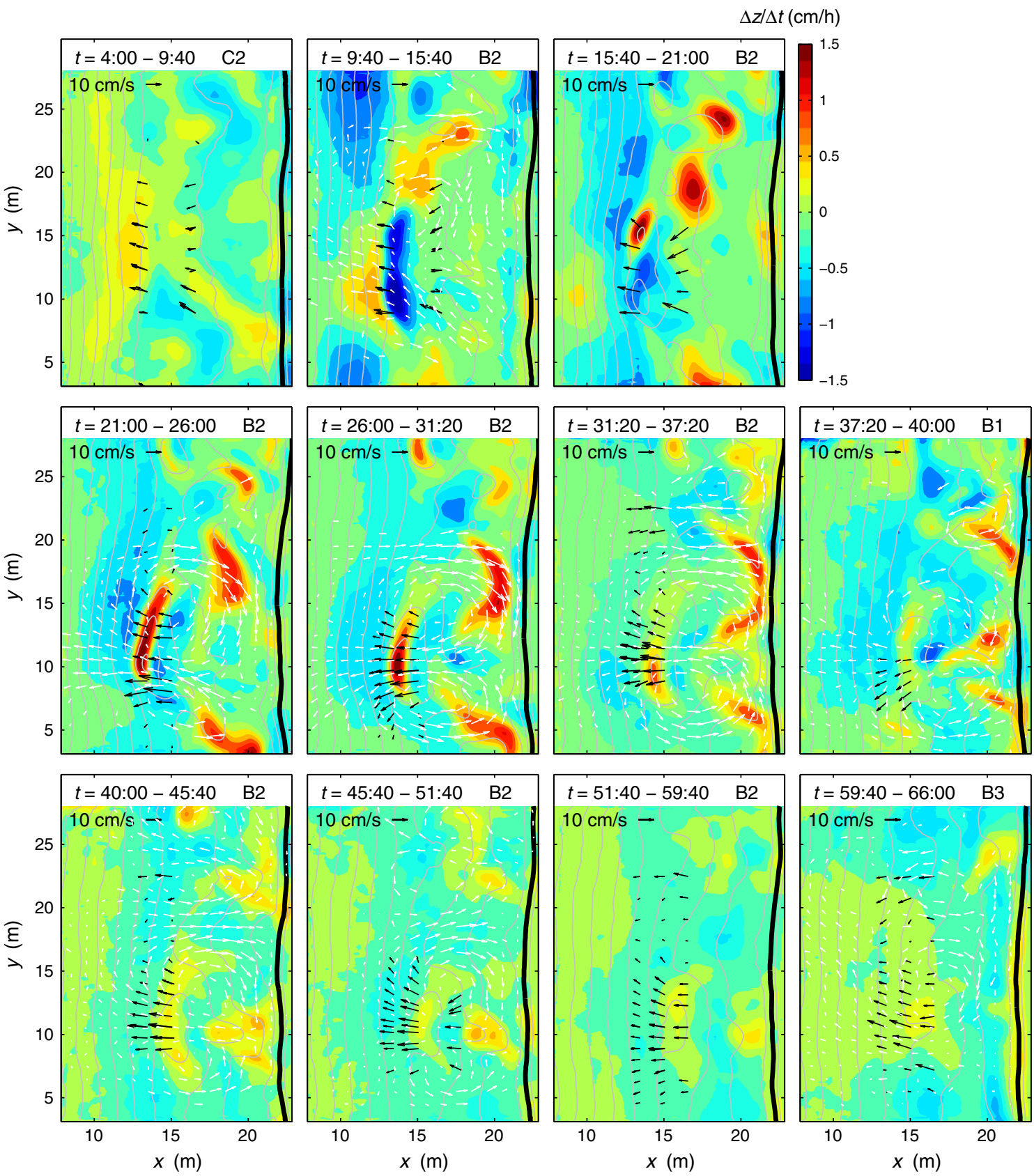

Figure 8. Bottom evolution velocity, with superimposed mean Eulerian (black arrows) and Lagrangian (white arrows) flow velocities, during the accretive sequence. Time interval $t$ refers to the initial and final times of the wave series, with indication of the corresponding wave climate. Isobaths every $4.5 \mathrm{~cm}$ are plotted in grey line, the shoreline is the thick black line.

beach exhibits an almost featureless terrace-like morphology as the two previously observed rip channels significantly fill up. These laboratory observations are essentially similar to the down-state sequence LBT-RBB-TBR-LTT sequence derived from visual observation of natural beaches [Wright and Short, 1984].

[27] Wave-driven circulations are superimposed on the bathymetries in Figure 7. Overall, the time evolution of Eulerian and Lagrangian mean flow patterns are consistent. Eulerian velocities are often stronger and systematically more offshore directed than Lagrangian velocities. This indicates that the mean current is not uniform over the vertical, larger values being reached just above the bottom boundary layer where Eulerian velocities were measured. At $t=4: 00$ and 9:40, alongshore variations in wave-driven current are small for the reasonably alongshore-uniform LBT beach state, which is not surprising. The situation is characterized by seaward oriented currents of about $10 \mathrm{~cm} \mathrm{~s}^{-1}$, except at $y \approx 22 \mathrm{~m}$ where mean flow magnitude is weak. By the time the LBT morphology has evolved into a RBB state at $t=15: 40$ and 21:00, the rip current circulation is slightly skewed with seaward velocities reaching $20 \mathrm{~cm} \mathrm{~s}^{-1}$. In contrast, for the evolving TBR beach state at $t=26: 00$ to 40:00, the rip current has a shore-normal orientation with its 
magnitude decreasing with time. For the subsequent weakly evolving LTT beach state at $t=45: 40$ to 59:40, a weak and substantially spread alongshore rip current is observed with a maximum velocity of about $12 \mathrm{~cm} \mathrm{~s}^{-1}$.

[28] The corresponding time evolution $\Delta z / \Delta t$, a measure of the rate at which the morphology evolves, is given in Figure 8. At $t=4: 00-9: 40$ (i.e., for $H_{m 0} \approx 17 \mathrm{~cm}$ and $T_{p}=2.1 \mathrm{~s}$ ), morphological changes are relatively small. At $t=9: 40-15: 40$ the morphological changes drastically increase as a result of the change in wave conditions, particularly that of the peak wave period $\left(H_{m 0} \approx 18 \mathrm{~cm}\right.$ and $T_{p}=3.5 \mathrm{~s}$ ). This corresponds to the LBT-RBB transition. For $t=15: 40-31: 20$, the horn and bay sequence continuously grows together with an onshore migration of the shoreward horns and a significant erosion of the seaward section of the bar (at about $10 \mathrm{~m}<x<14 \mathrm{~m}$ ) resulting in an overall onshore migration of the sandbar system. The lenticular sediment deposit onshore of the migrating shoal enlarges progressively (at about $18 \mathrm{~m}<x<21 \mathrm{~m}$ and $13 \mathrm{~m}<$ $y<20 \mathrm{~m}$ for $t=31: 20-37: 20$ ), presumably indicating an alongshore transport driven by the feeder currents. As the shoals attach to the shore at $t=37: 20-40: 00$, a rapid accretion of both the feeder channels and the more shoreward section is observed. Noteworthy, climate B1 was applied in that case (with a slightly different alongshore repartition in wave energy, see Figure 3). As a result, the orientation of the rip current is slightly modified and a weaker accretion at $(x \simeq 15 \mathrm{~m}, y \simeq 9 \mathrm{~m})$ and a larger erosion at $(x \simeq 16 \mathrm{~m}$, $y \simeq 11 \mathrm{~m}$ ) are observed in comparison to the preceding and following stages. For $t>40: 00$, the rate at which the beach evolves progressively decreases as a result of the slow TBRLTT transition. The main notable evolution is the accretion of the rip channels.

[29] Finally, the wave energy in the middle of the wave front was slightly decreased at $t=59: 40$ (condition B3). As a result, rip current intensity increased very slightly together with a more pronounced change of direction towards the center of the tank (see the two last panels in Figure 8). In addition, erosion/accretion patterns are slightly different for these two experiments, yet with a low rate of bottom changes. This gives an indication of the role of the wave front nonuniformity as a forcing template for the morphodynamics. Along with the observations made by changing the wave conditions from $\mathrm{B} 2$ to $\mathrm{B} 1$ described above, the trend during the TBR-LTT transition is that increasing the wave front nonuniformity tends to promote accretion in the middle of the basin and erosion on both sides.

\subsection{Erosive Sequence}

[30] Figure 9 shows the time evolution of the beach morphology for $H_{m 0} \approx 23 \mathrm{~cm}$ and $T_{p}=2.3 \mathrm{~s}$ at $66: 00<$ $t<100: 40$ with corresponding time evolution of erosion/accretion patterns. Results show an overall accretion and erosion at $8 \mathrm{~m}<x<14 \mathrm{~m}$ and $14 \mathrm{~m}<x<20 \mathrm{~m}$, respectively, corresponding to the offshore migration of the sandbar system. The rate at which the beach morphology evolves decreases with time. This suggests that the most rapid morphological adjustment occurs immediately after the change in wave conditions, which is in line with existing nonlinear morphodynamic modeling with time-varying wave conditions [Castelle and Ruessink, 2011]. At $t=100: 40$, the beach is not uniform alongshore. For instance, a rip channel and a shoal are observed at $y=23 \mathrm{~m}$ and $18 \mathrm{~m}$, respectively. This increasing beach three-dimensionality as a result of erosive conditions will be discussed later in section 6 .

[31] Mean circulations are more complex for the erosive sequence than for the accretionary sequence. A notable characteristic is that, despite an increase in wave height $\left(H_{m 0}=\right.$ $23 \mathrm{~cm}$ instead of $18 \mathrm{~cm}$ ), seaward flowing currents (about $10 \mathrm{~cm} \mathrm{~s}^{-1}$, see also Figure 5f) are systematically less intense than for the RBB and TBR beach states (rip current velocity of about $15-20 \mathrm{~cm} \mathrm{~s}^{-1}$ ) even when the beach is significantly alongshore variable (e.g., $t=92: 00)$. This is to some extent due to the shorter wave period ( $T_{p}=2.3 \mathrm{~s}$ instead of $\left.3.5 \mathrm{~s}\right)$. In addition, rip and feeder channels exhibit more variable patterns in terms of alongshore and cross-shore positions and orientation, therefore limiting the generation of coherent, intense, rip current circulations. At the beginning of the erosive sequence at $t=66: 00-72: 00$, two rip currents are observed at $y \approx 10$ and $22 \mathrm{~m}$. At $t=78: 20-84: 20$, a third one is observed at $y \approx 15 \mathrm{~m}$, as well as an onshore flow across the shoal at $y \approx 18 \mathrm{~m}$. At $t=92: 00-100: 40$, the three rips become narrower, with no significant increase in intensity. Overall, rip current circulations are highly variable during this erosive sequence.

\section{Detailed Hydrodynamics and Feedback Mechanisms}

[32] In this section, wave gauge measurements are used in order to analyze the processes that drives rip channel formation and subsequent evolution. Five distinct series of runs representative of the accretive sequence are selected. They correspond to the following: the initial state ("Longshore Bar Trough", $t \sim 5: 00$ ); the increase in wave forcing and the onset of three-dimensionality development ("Rhythmic Bar and Beach", $t \sim 13: 00$ ); the measured maximum in both beach three-dimensionality and rip intensity (during the RBB-"Transverse Bar and Rip" transition, $t \sim 23: 00$ ); the rip current system decay (TBR-"Low Tide Terrace" transition, $t \sim 34: 00$ ); and the final state (LTT, $t \sim 56: 00$ ).

[33] The corresponding time evolution of the measured horizontal distribution of significant wave height (determined from a zero-crossing analysis) is presented in Figure 10, row 1. Not surprisingly, smaller wave heights are measured for wave climate C2 (Figure 10, column 1) compared to the more energetic wave climate B2. The weaker energy imposed by the wavemaker in the middle of the tank $(y \approx 15 \mathrm{~m})$ and the friction along lateral walls result in an alongshore nonuniform wave height distribution along the seaward boundary of the surveyed region. This leads to a slightly alongshore nonuniform breaking zone, with a more pronounced wave steepening on both sides $(y \simeq 9 \mathrm{~m}$ and $y \simeq 21 \mathrm{~m}$ ) and a more progressive dissipation at the center. For the RBB and TBR states, wave heights are larger in the surf zone in the alignment of the rip at $y \simeq 10 \mathrm{~m}$ than across the shoals due to less intense breaking-induced wave dissipation in the deep rip channel (Figures 10, row 1, columns 3 and 4). Overall, the wave height decay in the surf zone is more progressive for the LTT situation (Figure 10, column 5) than for the others, indicating that the breaking progressively switches from plunging type to spilling type during the accretive sequence. 

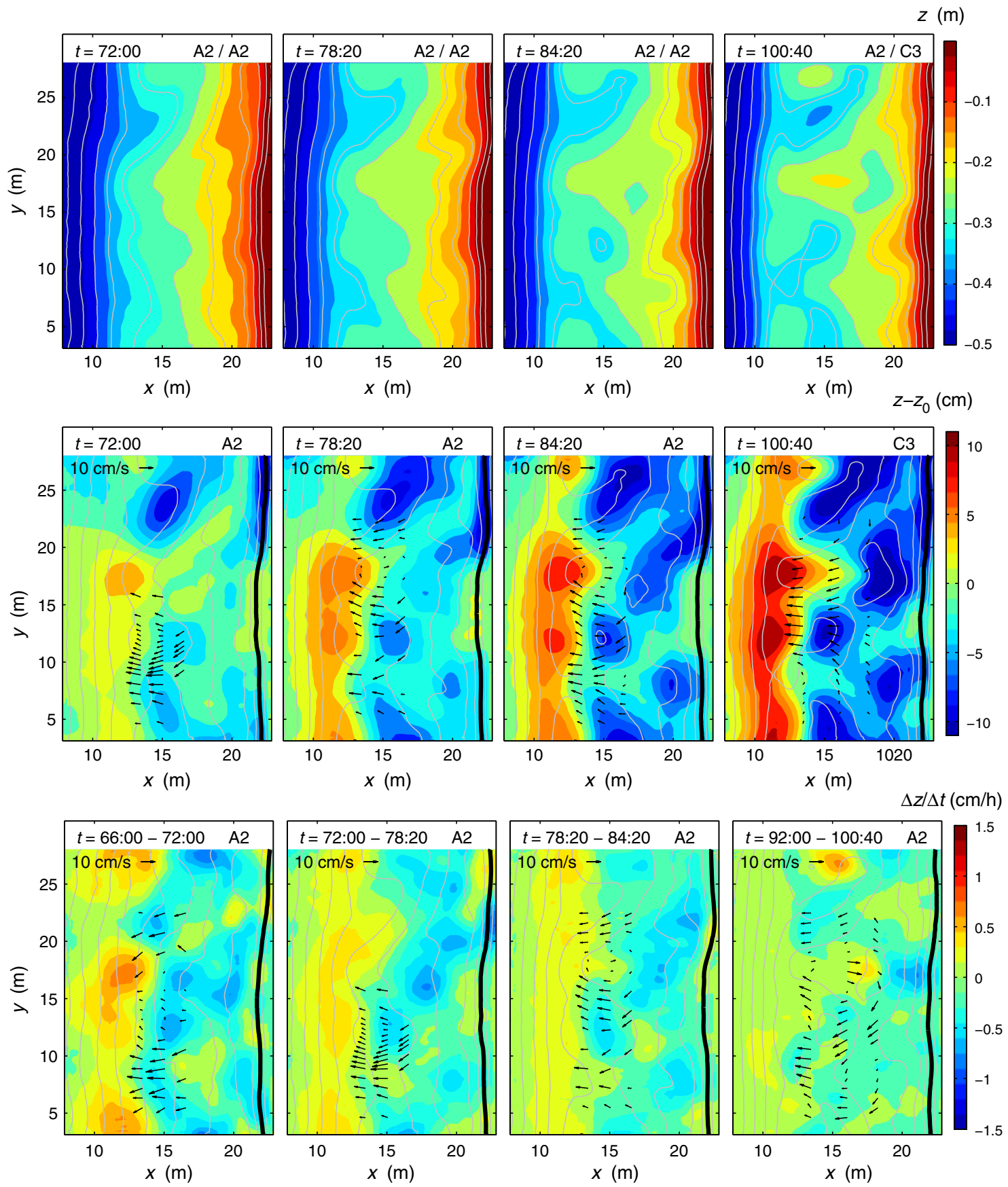

Figure 9. Same as in Figures 6, 7, and 8 for the erosive sequence.

[34] Orbital velocities are plotted in Figure 10, row 2 with superimposed circulations. Because the three velocimeters covered a limited area of the region of interest, here we estimated the cross-shore orbital velocities from the free surface elevation measurements. Each frequency component of the wave gauge signal was transformed into velocity at $5 \mathrm{~cm}$ above the bed using linear shallow water wave theory. This method was checked to correctly estimate the crossshore component of the velocities where Eulerian velocities were measured. The orbital velocity is thus estimated as $U_{m}=2^{1 / 2} \sigma(u)$, where $u(t)$ is the high-pass filtered $\left(f>T_{p} / 2\right)$ recomposed cross-shore horizontal velocity. Largest values are observed just before wave breaking, in particular where the sandbar morphology is pronounced (21:00 $<t<26: 00$ at $x \simeq 12 \mathrm{~m}, y \simeq 12 \mathrm{~m}$ ). The orbital velocities are also relatively large across the shoals and in the surf zone at the end of the sequence.

[35] The time evolution of the velocity skewness at the bed $\left(S k_{b}\right)$ is shown in Figure 10, row 3. The velocity skewness $(S k)$ is defined as

$$
S k=\frac{\left\langle(u-\langle u\rangle)^{3}\right\rangle}{\left\langle(u-\langle u\rangle)^{2}\right\rangle^{3 / 2}}
$$



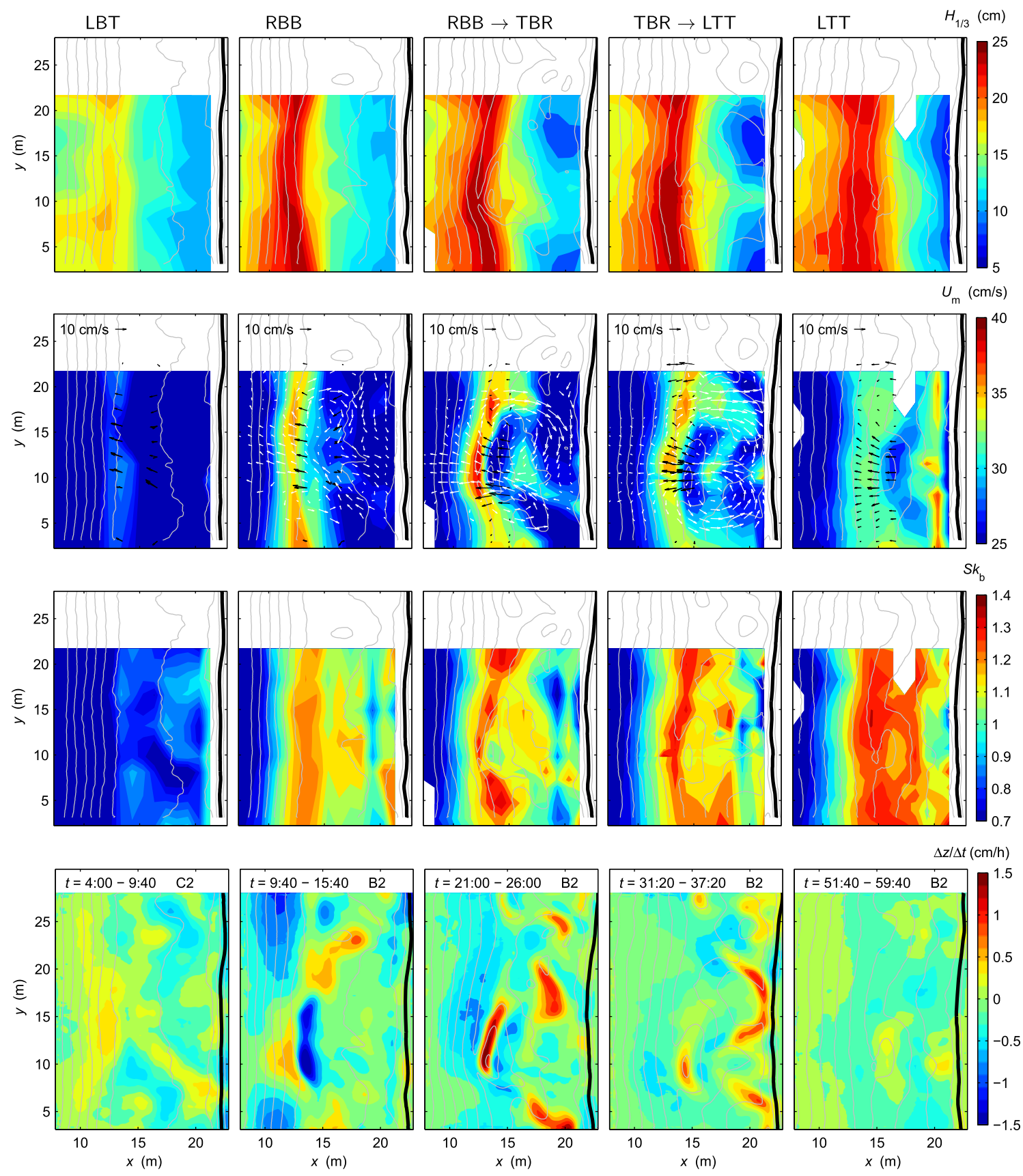

Figure 10. From top to bottom: (row 1) significant wave height, (row 2) orbital velocity with superimposed mean Eulerian (black arrows) and Lagrangian (white arrows) flow velocities, (row 3) velocity skewness, and (row 4) bottom evolution velocity, during the accretive sequence. Time interval $t$ refers to the initial and final times of the wave series, with indication of the corresponding wave climate. Isobaths every $4.5 \mathrm{~cm}$ are plotted in grey line, the shoreline is the thick black line.

where $\langle$.$\rangle is denoting a time-averaging over the 20 \mathrm{mn}$ wave series. The wave asymmetry reads

$$
A_{s}=-\frac{\left\langle\mathcal{H}(u)^{3}\right\rangle}{\left\langle(u-\langle u\rangle)^{2}\right\rangle^{3 / 2}}
$$

where $\mathcal{H}$ is the imaginary part of the Hilbert transform. Following earlier works by Elgar [1987] and Henderson et al. [2004], Berni et al. [2013] showed that asymmetry is transferred into velocity skewness within the bottom boundary layer, which effect could explain how asymmetric waves promote on-shore sediment transport. A linear relation was found between the velocity skewness at the bed $S k_{b}$ and the wave nonlinearities $\left(S k, A_{s}\right)$ measured above the boundary layer:

$$
S k_{b}=S k\left(\cos \phi+\sin \phi \frac{A_{s}}{S k}\right),
$$

where $\phi$ is of about 30 to $40^{\circ}$, presumably also depending on the Reynolds number and the bed roughness. Here $S k_{b}$ is computed with $\phi=40^{\circ}$ (Figure 10 , row 3). At the 
beginning of the down-state sequence, $S k_{b}$ values are rather small. Larger values are obtained just after breaking at $x \simeq 15 \mathrm{~m}$. In the surf zone, areas of low $S k_{b}$ closely match accretion patterns (Figure 10, row 4). During the initial development of a crescentic pattern (9:40<t<15:40), $S k_{b}$ is reasonably uniform alongshore with largest values measured at breaking across the sandbar $(x \simeq 13 \mathrm{~m})$. In contrast, at this cross-shore location, mean offshore-directed flow velocities are not uniform alongshore with largest flow magnitude at $10 \mathrm{~m} \leq y \leq 15 \mathrm{~m}$. This corresponds to the maximum erosion patterns shown in Figure 10, row 4. The combined effects of wave-breaking-induced turbulence and wave nonlinearities promote sediment pick-up [Berni et al., 2012]. The suspended sediment is then likely transported by the mean flow, partly deposited off-shore in the alignment of the rip at $x \simeq 11 \mathrm{~m}, y \simeq 10 \mathrm{~m}$ and partly transported by the circulation cells and further deposited in the regions of decreasing $S k_{b}$ values (i.e., negative $\partial S k_{b} / \partial x$ gradients) and weak mean flows $(x \simeq 16 \mathrm{~m}, y \simeq 3 \mathrm{~m}$, and $y \simeq 20 \mathrm{~m}$ ). In addition, large $S k_{b}$ values at $x \simeq 17 \mathrm{~m}, y \simeq 10 \mathrm{~m}$ combine with onshore oriented mean velocities and are associated to the rip channel formation. This corresponds to the onset of the positive feedback mechanism characterized by an increase in rip intensity, beach three-dimensionality and beach changes rate (see Figure 5).

[36] The most spatially variable $S k_{b}$ patterns are measured during the RBB-TBR transition (Figure 10, column 3) characterized by maximum rip intensity and rate of bottom changes. The largest and smallest $S k_{b}$ values are observed across the crescentic bar and shoreward of the horns, respectively. The seabed accretion patterns shown in Figure 10, row 4 clearly correspond to areas of both decreasing $S k_{b}$ values (negative $\partial S k_{b} / \partial x$ ) and decreasing intensity of wave-driven mean currents. This further illustrates that wave-induced circulations and near-bed velocity skewness may combine in order to get large and rapid evolutions of the beach patterns. At this stage $(t \sim 23: 00)$, the bed form growth saturates and the crescentic bar system starts to migrate on shore. The near-bed velocity skewness being large over the crescentic bar, it likely promotes on-shore sediment transport that counteracts the off-shore transport induced by the mean currents. This corresponds to the end of the primacy of the positive feedback mechanism.

[37] In the remaining (negative feedback) stage of the accretive sequence ( $t \geq 31: 20$ in Figure 10), velocity skewness patterns tend to become more uniform alongshore together with an overall decrease in wave-driven circulation intensity. In the final stage of the down-state sequence (Figure 10, column 5), the patterns of largest $S k_{b}$ values roughly match erosion patterns. These observations suggest that near-bed wave nonlinearities are a key process to the negative feedback mechanism during the TBR-LTT sequence.

[38] Simultaneously increasing wave height and decreasing wave period leads to an overall erosion of the beach face (Figure 9). During this up-state sequence, the cross-shore distribution of the wave height (Figure 11, row 1) suggests that breaking type changed progressively from spilling to plunging. The orbital velocities are relatively weak at the beginning of the sequence and significantly increased by the end of the sequence with a maximum across the sandbar crest at $x \simeq 11 \mathrm{~m}$. This sequence is characterized
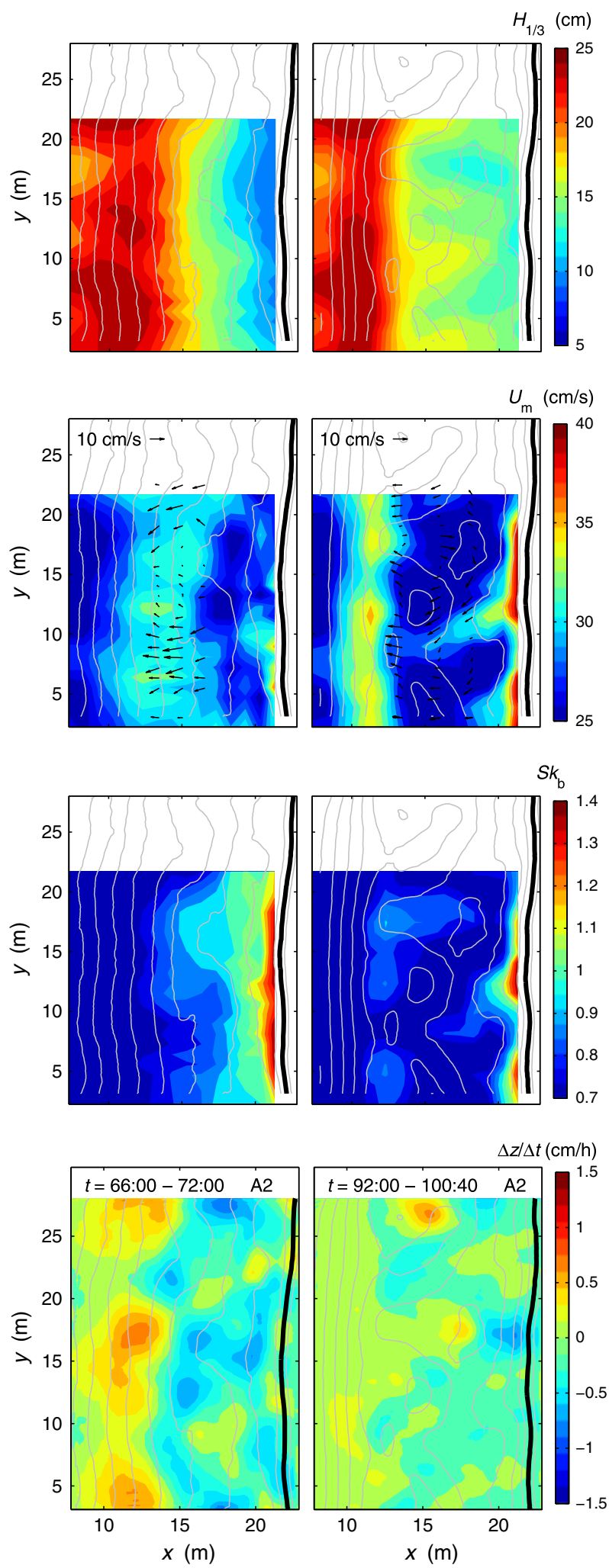

Figure 11. Same as in Figure 10 for the erosive sequence.

by an increase in both beach three-dimensionality and wave-driven circulation intensity (see bottom changes and flow patterns in Figure 11). Here, the final stage $(92: 00<$ $t<100: 40)$ is characterized by rather large offshore mean velocities and smaller wave nonlinearities compared to 
66:00 $<t<72: 00$. This results in an overall decrease in the rate of bottom changes. Yet, bottom changes remain significant, meaning that a morphological equilibrium with wave forcing is not reached.

[39] As a final remark to this section, wave set-up and low-frequency wave energy distributions were also analyzed in detail (not shown). These quantities vary in the crossshore direction but only very slightly alongshore, and no clear relationship with the three-dimensional beach evolutions was found.

\section{Discussion in the Framework of Intermediate Beach State Scheme}

[40] The accretionary sequence quantitatively described in this paper is essentially similar to the sequential intermediate beach state classification scheme qualitatively derived from visual observations on natural beaches in Wright and Short [1984]. The full, accretionary, down-state sequence LBT-RBB-TBR-LTT has been obtained for time-invariant shore-normal irregular waves as a result of the feedback between hydrodynamics, sediment transport, and the evolving bathymetry. According to our findings, this down-state sequence can be further divided into the LBT-RBB-TBR and the TBR-LTT sequences that are governed by a positive and negative feedback mechanism, respectively.

[41] At the beginning of the sequence, the LBT morphology evolves into a RBB state as the shore-parallel bar progressively migrates onshore along with the development of horns and bays. These patterns resemble those obtained through linear stability analysis when addressing the development of crescentic sandbars [e.g., Falqués et al., 2000; Calvete et al., 2005]. Despite the constraints of the basin walls, the subsequent evolution into a TBR state is once again in line with, nonlinear, morphodynamic modeling exercises in terms of rip current circulation patterns and bar and rip morphology at saturation [e.g., Garnier et al., 2008; Castelle and Ruessink, 2011]. A notable characteristic of the TBR state is the presence of a well-developed rip head bar seaward in a relatively shore-normal orientation aligned with the rip neck. This rip head bar is similar in patterns with numerical works [Castelle and Ruessink, 2011] and confirms that it is likely an important component of the rip system evolution [Brander, 1999]. Both linear and nonlinear stability studies assumed that the cross-shore sediment transport driven onshore by wave nonlinearities and offshore by the undertow are in balance for a given equilibrium beach profile. Our results are in line with existing nonlinear modeling studies [e.g., Garnier et al., 2008] showing that the positive feedback between waves, currents and the morphological response is the primary driving mechanism for the down-state LBT-RBB-TBR transition. In addition, we found that both the most intense rip intensity and the highest rate at which the morphology evolves are observed during the RBB-TBR transition.

[42] The subsequent TBR-LTT transition is characterized by the following: (1) the filling of the feeders and rip channels, (2) the welding of the rip head bar to the longshore bar, (3) a rapid decrease in the rate at which the bathymetry evolves, and (4) a decreasing intensity of the rip velocity and an increasing alongshore spreading of the rip neck. From a morphological point of view, the TBR-LTT sequence is in agreement with the field observations of Brander [1999]. Contrariwise, a major difference with the findings of Brander [1999] is that both Eulerian and Lagrangian measurements show that rip current intensity decreases as the TBR morphology evolves into a LTT state. As the latter transition is characterized by a decrease of both beach three-dimensionality and the rate at which the morphology is changing, the TBR-LTT is governed by a negative feedback mechanism. This occurs as the overall accretion is fairly completed. The increasing intensity in wave nonlinear effects on sediment transport most likely contributes to this negative feedback mechanism. This hypothesis must be tested with a morphodynamic model of 3-D surf zone sandbars accounting for the sediment transport driven by wave nonlinearities. To date, those models did not fully account for these cross-shore processes, which can explain why they failed to reproduce the TBR-LTT transition for shore-normal waves. Accordingly, the hydrodynamic and morphology data collected in our experiment will serve as a benchmark for the models to address this negative feedback mechanism, which is a challenge to future morphodynamic model applications.

[43] For the erosive sequence, our small-scale model results do not seem in agreement with existing upstate sequence schemes along open beaches [Wright and Short, 1984]. We do observe an overall seaward migration of the sandbar during the erosive sequence but, conversely to Wright and Short [1984], the morphological evolution is characterized by an increase of beach threedimensionality instead of the reshaping of the bar into an alongshore-uniform pattern. Three potential explanations can be proposed. (1) It has been shown that, conversely to open beaches, sandbar three-dimensionality increases with increasing wave energy on embayed beaches as a result of geological constraints (e.g., headlands). This has been reported along the SW coast of France [Enjalbert et al., 2011] and along embayed beaches in UK (Gerd Masselink, personal communication, 2012). As the lateral boundaries in our physical model act as headlands, this could explain the increase in beach three-dimensionality during the erosive sequence. Using the nondimensional embayment scaling parameter $\delta$ in Castelle and Coco [2012], that was slightly modified from the former proposed by Short and Masselink [1999], we find $\delta \approx 5$ for the erosive sequence and the basin dimensions. This corresponds to "cellular beach circulation," that is, wave-driven circulations that are strongly constrained by alongshore length of the beach with the presence of one or two rip channels. For instance, for a similar $\delta$, Loureiro et al. [2012] observed the formation of large 3-D features at Arrifana (Portugal) during a severe storm with $H_{s}>5 \mathrm{~m}$. (2) Another explanation is that the alongshore current driven by obliquely incident large waves often drives the straightening of the sandbars. In this case, the morphology evolves into an erosive TBR (eTBR) rather than a LBT state [Price and Ruessink, 2011]. These conditions were not met in the present study as a result of both the shore-normal incidence used throughout our experiments and the presence of the basin wall at the lateral boundaries. (3) Beaches along open coasts are typically characterized by a system reset during extreme storm waves (i.e., decrease in beach three-dimensionality as a result of the up-state sequence towards a LBT state, Wright and Short [1984]; Van 
Enckevort et al. [2004]). Splinter et al. [2011] also showed that the presence of sustained shore-normal large waves can develop sandbar three-dimensionality. Accordingly, we can expect that the wave climate during the erosive sequence did not reach the threshold in significant wave height that would make the LTT morphology evolve into the LBT state. Instead, the morphology presumably evolved into a TBR state, and was therefore characterized by an increase in beach three-dimensionality.

[44] The two latter explanations constitute the most likely hypothesis. Accordingly, an incomplete (LTT-TBR) up-state sequence has been depicted in our physical experiment. The up-state LTT-LBT and LTT-eTBR sequences, both characterized by a decrease in beach three-dimensionality, would have required higher waves [Van Enckevort et al., 2004] and oblique incidence [Price and Ruessink, 2011], respectively.

\section{Conclusions}

[45] Our experiments provide the first extensive measurements of hydrodynamics and beach morphology through all the states within the intermediate beach classification [Wright and Short, 1984] during both up-state and downstate transitions. The detailed analysis of combined hydrodynamics and morphodynamics suggests the subtle interplay between several feedback mechanisms associated to wavedriven rip current circulations, wave nonlinearities, sediment transport, and the seabed evolution.

[46] Any change in prevailing wave conditions immediately increases the rate at which the beach morphology evolves. Conversely, running the same wave climate for a long time systematically resulted in a progressive decrease in the bottom evolution velocity, indicating that the beach likely tends towards a steady state that is not systematically uniform alongshore. A full down-state sequence (LBTRBB-TBR-LTT), characterized by an overall accretion of the beach, has been analyzed. We showed that down-state sequence can be further divided into the LBT-RBB-TBR and the TBR-LTT sequences that are governed by a positive and a negative feedback mechanism, respectively. An incomplete (LTT-TBR) up-state, erosive, sequence has also been analyzed.

[47] To date, nonlinear morphodynamic model cannot reproduce the range of dynamics related to intermediate beach morphodynamics. The detailed hydrodynamic and morphology data collected in our experiments will serve as an important benchmark for numerical models. Numerical models will be used to further test the hypothesis we raised concerning the respective contribution of wave-driven circulation and wave nonlinearities to the positive and negative feedback mechanisms involved in both down-state and up-state beach sequences.

[48] Acknowledgments. The experiments were undertaken within the framework of the Project MODLIT (RELIEFS/INSU, SHOM-DGA) with additional financial support from COPTER (ANR). The authors greatly acknowledge SOGREAH Consultants for technical support when constructing the physical model, especially the assistance provided by G. Excoffier and L. Marcellin. The authors are also thankful to all the people involved in this experiment. Additional financial support during the writing of the manuscript has been provided through the projects BARBEC (ANR ${ }^{\circ} 2010$ JCJC 602 01) and BARCAN (INSU/LEFE). The constructive criticisms of the reviewers and the editors are greatly appreciated.

\section{References}

Austin, M., T. M. Scott, J. W. Brown, J. A. Brown, J. H. MacMahan, G. Masselink, and P. Russell (2010), Temporal observations of rip current circulation on a macro-tidal beach, Cont. Shelf Res., 30, 1149-1165, doi:10.1016/j.csr.2010.03.005.

Berni, C., H. Michallet, and E. Barthélemy (2012), Measurements of surf zone sand bed dynamics under irregular waves, Eur. J. Environ. Civ. Eng., 16(8), 981-994, doi:10.1080/196481892012.705957.

Berni, C., E. Barthélemy, and H. Michallet (2013), Surf zone cross-shore boundary layer velocity asymmetry and skewness: An experimental study on a mobile bed, J. Geophys. Res. Oceans, 118, 2188-2200, doi:10.1002/jgrc.20125

Brander, R. W. (1999), Field observations on the morphodynamic evolution of a low-energy rip current system, Mar. Geol., 157, 199-217.

Brander, R. W., and A. D. Short (2000), Morphodynamics of a large-scale rip current system at Muriwai Beach, New Zealand, Mar. Geol., 165, 27-39.

Brander, R. W., and A. D. Short (2001), Flow kinematics of low-energy rip current systems, J. Coastal Res., 17, 468-481.

Bruneau, N., B. Castelle, P. Bonneton, R. Pedreros, R. Almar, N. Bonneton, P. Bretel, J. P. Parisot, and N. Sénéchal (2009), Field observations of an evolving rip current on a meso-macrotidal well-developed inner bar and rip morphology, Cont. Shelf Res., 29, 1650-1662.

Bruneau, N., P. Bonneton, B. Castelle, and R. Pedreros (2011), Modeling rip current circulations and vorticity in a high-energy mesotidal-macrotidal environment, J. Geophys. Res., 116, C07026, doi:10.1029/2010JC006693.

Calvete, D., N. Dodd, A. Falqués, and S. M. van Leeuwen (2005), Morphological development of rip channel systems: Normal and near-normal wave incidence, J. Geophys. Res., 110, C10006, doi:10.1029/2004JC002803.

Castelle, B., and B. G. Ruessink (2011), Modeling formation and subsequent nonlinear evolution of rip channels: Time-varying versus time-invariant wave forcing, J. Geophys. Res., 116, F04008, doi:10.1029/2011JF001997.

Castelle, B., B. G. Ruessink, P. Bonneton, V. Marieu, N. Bruneau, and T. D. Price (2010a), Coupling mechanisms in double sandbar systems, Part 2: Impact on alongshore variability of inner-bar rip channels, Earth Surf. Processes Landforms, 35, 771-781.

Castelle, B., and G. Coco (2012), The morphodynamics of rip channels on embayed beaches, Cont. Shelf Res., 43, 10-23.

Castelle, B., H. Michallet, V. Marieu, F. Leckler, B. Dubardier, A. Lambert, C. Berni, P. Bonneton, E. Barthélemy, and F. Bouchette (2010b), Laboratory experiment on rip current circulations over a moveable bed: Drifter measurements, J. Geophys. Res., 115, C12008, doi:10.1029/2010JC006343.

Coco, G., and A. B. Murray (2007), Patterns in the sand: From forcing templates to self-organization, Geomorphology, 91, 271-290, doi:10.1016/j.geomorph.2007.04.023.

Dalrymple, R. A., J. H. MacMahan, A. J. H. M. Reniers, and V. Nelko (2011), Rip currents, Annu. Rev. Fluid Mech., 43, 551-581.

Deigaard, R., N. Drønen, J. Fredsøe, J. H. Jensen, and M. P. Jørgensen (1999), A morphological stability analysis for a long straight barred coast, Coastal Eng., 36, 171-195.

Drønen, N., and R. Deigaard (2007), Quasi-three-dimensional modelling of the morphology of longshore bars, Coastal Eng., 54, 197-215.

Elgar, S. (1987), Relationships involving third moments and bispectra of a harmonic process, IEEE Trans. Acoust. Speech Signal Process., ASSP35, 12, 1725-1726.

Enjalbert, C., B. Castelle, D. Rihouey, and D. Dailloux (2011), Highfrequency video observation of geologically-constrained barred-beach: La Grande Plage de Biarritz (France), J. Coastal Res., SI 64, 70-74.

Falqués, A., G. Coco, and D. A. Huntley (2000), A mechanism for the generation of wave-driven rhythmic patterns in the surf zone, J. Geophys. Res., 105(C10), 24071-24087, doi:10.1029/2000JC900100.

Garnier, R., D. Calvete, A. Falqués, and N. Dodd (2008), Modelling the formation and the long-term behavior of rip channel systems from the deformation of a longshore bar, J. Geophys. Res., 113, C07053, doi:10.1029/2007JC004632.

Garnier, R., N. Dodd, A. Falqués, and D. Calvete (2010), Mechanisms controlling crescentic bar amplitude, J. Geophys. Res., 115, F02007, doi:10.1029/2009JF001407.

Grasso, R., H. Michallet, E. Barthélemy, and R. Certain (2009), Physical modeling of intermediate cross-shore beach morphology: Transient and equilibrium states, J. Geophys. Res., 114, C09001, doi:10.1029/2009JC005308.

Grasso, R., H. Michallet, and E. Barthélemy (2011a), Experimental simulation of shoreface nourishments under storm events: A morphological, hydrodynamic, and sediment grain size analysis, Coastal Eng., 58, 184-193. 


\section{MICHALLET ET AL.: RIP CURRENT LABORATORY EXPERIMENT}

Grasso, R., H. Michallet, and E. Barthélemy (2011b), Sediment transport associated with morphological beach changes forced by irregular asymmetric, skewed waves, J. Geophys. Res., 116, C03020, doi:10.1029/2010JC006550.

Guannel, G., H. T. Ozkan-Haller, M. C. Haller, and J. T. Kirby (2007), Influence of velocity moments on sand bar movement during CROSSTEX, Proceedings of Coastal Sediments'07, pp. 28-41, ASCE, Reston, Va

Haas, K. A., and I. A. Svendsen (2002), Laboratory measurements of the vertical structure of rip currents, J. Geophys. Res., 107(C5), 3047, doi:10.1029/2001JC000911.

Haas, K. A., I. A. Svendsen, M. Haller, and Q. Zhao (2003), Quasi-threedimensional modeling of rip current systems, J. Geophys. Res., 108(C7), 3217, doi:10.1029/2002JC001355.

Haas, K. A., and J. C. Warner (2009), Comparing a quasi-3D to a full 3D nearshore circulation model: SHORECIRC and ROMS, Ocean Modell., 26, 91-103.

Haller, M. C., and R. A. Dalrymple (2001), Rip current instabilities, J. Fluid Mech., 433, 161-192.

Hamm, L. (1992), Directional nearshore wave propagation over a rip channel: An experiment, Proceedings of 23rd International Conference on Coastal Engineering, pp. 226-239, ASCE, New York.

Henderson, S. M., J. S. Allen, and P. A. Newberger (2004), Nearshore sandbar migration predicted by an eddy-diffusive boundary layer model, $J$ Geophys. Res., 109, C06024, doi:10.1029/2003JC002137.

Holman, R. A., G. Symonds, E. B. Thornton, and R. Ranasinghe (2006), Rip spacing and persistence on an embayed beach, J. Geophys. Res., 111, C01006, doi:10.1029/2005JC002965.

Kennedy, A. B., and D. Thomas (2004), Drifter measurements in a laboratory rip current, J. Geophys. Res., 109, C08005, doi:10.1029/ 2003JC001927.

Lippmann, T. C., and R. A. Holman (1990), The spatial and temporal variability of sand bar morphology, J. Geophys. Res., 95(C7), 11575-11590, doi:10.1029/JC095iC07p11575.

Loureiro, C., O. Ferreira, and J. A. G. Cooper (2012), Extreme erosion on high-energy embayed beaches: Influence of megarips and storm grouping, Geomorphology, 139-140, 155-171.

MacMahan, J. H., A. J. H. M. Reniers, E. B. Thornton, and T. P. Stanton (2004a), Infragravity rip current pulsations, J. Geophys. Res., 109, C01033, doi:10.1029/2003JC002068.

MacMahan, J. H., A. J. H. M. Reniers, E. B. Thornton, and T. P. Stanton (2004b), Surf zone eddies coupled with rip current morphology, J. Geophys. Res., 109, C07004, doi:10.1029/2003JC002083.

MacMahan, J. H., E. B. Thornton, T. P. Stanton, and A. J. H. M. Reniers (2005), RIPEX: Observations of a rip current system, Mar. Geol., 218, $113-134$.
MacMahan, J. H., E. B. Thornton, and A. J. H. M. Reniers (2006), Rip current review, Coast. Eng., 53, 191-208.

Masselink, G., and A. D. Short (1993), The effect of tide range on beach morphodynamics and morphology: A conceptual beach model, J. Coastal Res., 9, 785-800.

Price, T. D., and B. G. Ruessink (2011), State dynamics of a double sandbar system, Cont. Shelf Res., 31, 659-674.

Ranasinghe, R., G. Symonds, K. Black, and R. Holman (2004), Morphodynamics of intermediate beaches: A video imaging and numerical modelling study, Coast. Eng., 51, 629-655.

Reniers, A. J. H. M., J. H. MacMahan, E. B. Thornton, T. P. Stanton, M. Henriquez, J. W. Brown, J. A. Brown, and E. Gallagher (2009), Surf zone surface retention on a rip-channeled beach, J. Geophys. Res., 114 C10010, doi:10.1029/2008JC005153.

Scott, T., P. Russell, G. Masselink, A. Woolers, and A. Short (2007), Beach rescue statistics and their relation to nearshore morphology and hazards: A case study for southwest England, J. Coast. Res., SI 50, 1-6.

Sénéchal, N. T. Gouriou, B. Castelle, J. P. Parisot, S. Capo, S. Bujan, and H. Howa (2009), Morphodynamic response of a meso- to macro-tidal intermediate beach based on a long-term dataset, Geomorphology, 107, 263-274

Short, A. D., and G. Masselink (1999), Embayed and structurally controlled embayed beaches, in Handbook of Beach and Shoreface Morphody namics, edited by Short, A. D., pp. 230-250, John Wiley, Chichester, U. K.

Smit, M. W. J., A. J. H. M. Reniers, B. G. Ruessink, and J. A. Roelvink (2008), The morphological response of a nearshore double sandbar system to constant wave forcing, Coast. Eng., 55, 761-770.

Splinter, K. D., R. A. Holman, and N. G. Plant (2011), A behavior-oriented dynamic model for sandbar migration and $2 \mathrm{DH}$ evolution, J. Geophys. Res., 116, C01020, doi:10.1029/2010JC006382.

Thornton, E. B., J. MacMahan, and A. H. Sallenger Jr. (2007), Rip currents, mega-cusps, and eroding dunes, Mar. Geol., 240, 151-167.

Tiessen, M. C. H., N. Dodd, and R. Garnier (2011), Development of crescentic bars for a periodically perturbed initial bathymetry, J. Geophys. Res., 116, F04016, doi:10.1029/2011JF002069

Van Enckevort, I. M. J., B. G. Ruessink, G. Coco, K. Susuki, I. L. Turner, N. G. Plant, and R. A. Holman (2004), Observations of nearshore crescentic sandbars, J. Geophys. Res., 109, C06028, doi:10.1029/2003JC002214.

Wang, T., and N. C. Kraus (2005), Beach profile equilibrium and patterns of wave decay and energy dissipation across the surf zone elucidated in a large-scale laboratory experiment, $J$. Coast. Res., 21, 522-534.

Wright, L. D., and A. D. Short (1984), Morphodynamic variability of surf zones and beaches: A synthesis, Mar. Geol., 56, 93-118. 